\title{
Using ARGO, GRACE and altimetry data to assess the quasi stationary North Atlantic circulation
}

\author{
F. Richter, D. Sidorenko, S. Danilov, J. Schröter
}

Alfred-Wegener-Institute for Polar- and Marine Research, Bussestrasse 24, D-27570

Bremerhaven, Germany, Falk.Richter@awi.de

\section{Summary}

We analyse the North Atlantic circulation by combining data from ARGO profiling buoys and satellite altimetry measurements into an inverse finite-element ocean circulation model. The model solution is consistent with ocean dynamics and approximate conservation of temperature and salinity. The ocean circulation is analysed separately for the years 2005 and 2006. Temperature and salinity fields found as solution are close to ARGO data and correspond to a large-scale ocean circulation with a surface elevation close to the altimeter measurements. Numerical experiments carried out with and without use of the altimetric data are discussed. Including altimetry is shown to improve the model solutions, in particular, producing more realistic heat transports. The analysed temperature and salinity fields that minimize the model/data misfit are discussed. It is found that both types of observations are to a large extent complementary to each other.

\section{Introduction}

In the last years, two major observation systems have become operational. The first, satellite altimetry, maps the ocean surface quasi synoptically, and by referencing sea surface height to the GRACE geoid ocean currents are diagnosed. The second observing system is the Global Array of Profiling Floats (ARGO) adding in situ subsurface temperature and salinity data. Both types of measurements are consistent with each other to such an extent that altimetry can be used to check the quality and performance of individual temperature and salinity profiles measured by ARGO (see e.g. Ivchenko et al., 2007; Guinehut et al., 2009). It is shown that both types of measurements complement each other and a joint analysis is required in order to fully exploit the information content. 
We combine the two sources of data in the context of an ocean inverse general circulation model. In this way we make use of dynamical rather than statistical correlations between the data and analyse ocean currents and transports simultaneously with the observations.

Generally, numerical ocean circulation models produce fields which differ from observations. The bias is a result of many factors, which are in both, models and measurements. On one hand models produce uncertainties due to the lack of sufficient information on the surface forcing and errors in model dynamics. On the other hand, the measurements themselves are contaminated by measurement errors and include transient effects of the ocean dynamics which are not resolved by models. Assimilating all available information into an ocean circulation model could serve the purpose of finding the compromise between model and data and obtaining improved patterns of ocean circulation. This has been successfully demonstrated in a series of works (Wenzel et al., 1998, 2001, 2002; Stammer et al. 2002, 2003; Losch et al. 2004; Kivman et al., 2005).

\section{Model setup and data}

The model used for the present study is an inverse finite-element ocean circulation model (IFEOM) which has been described in Sidorenko et al. (2005). The model solves the stationary momentum equations for velocity field and sea surface height, and treats the advective-diffusive tracer balances as soft constraints. IFEOM seeks for the temperature (T) and salinity (S) fields which give minimum to its objective function. The latter penalizes residuals in the tracer equations, deviations of model variables from data available and also the misfit between the diagnosed deep pressure gradient and the pressure gradient of a prognostic model run. The experiments reported below take into account several data sources. Gouretsky and Koltermann (2004) climatology is used in all experiments as a background for temperature and salinity.

The other dataset includes $\mathrm{T}$ and S profiles for the years 2005-2006 from the ARGO project, available from the official ARGO web site (www.ARGO.ucsd.edu). The ARGO data comes from a set of profiling buoys which contains seasonal and transient signals. Because of a poor spatial coverage of ARGO data on a monthly basis we restrict our results to annual model solutions. We use the annual mean of ARGO data in our experiments with the seasonal signal removed.

Altimetry data is optionally taken as gridded maps of absolute dynamic topography (MADT) provided by AVISO (Archiving, Validation and Interpretation of Satellite Oceanographic data). Absolute dynamic topography is the sum of sea level anomaly (SLA) and a mean dynamic topography (MDT). Following AVISO the Rio05 MDT is used here. The Rio05 mean dynamic topography (Rio and Hernandez, 2004 and Rio et al., 2005) is the combined product of large scale MDT, 
using the CLS01 mean sea surface (MSS) and the EIGEN-GRACE 03S geoid (Reigber et al., 2005), and hydrographic and Lagrangian data together with altimeter SLA over the 1993-2002 period. CLS01 shows the mean shape of the sea surface during the period covered by the altimetry data. It is corrected from seasonal variations and corresponds to the sum of geoid + mean elevation in response to ocean circulation. The annual means of MADT have been computed for the years 2005-2006.

Three experiments have been performed for each year for the period 20052006. First, solutions are obtained by assimilating only the ARGO data (ARGO05-ARGO06). Second, solutions that use only altimetry data (Alt05-Alt06) are found. Finally, solutions using both, ARGO and altimetry are computed (AltARGO05-AltARGO06). In the following, the adjustments produced by IFEOM in temperature and salinity fields and the resulting circulation patterns are analysed.

\section{Results}

The sea surface elevation corresponding to the analysis of ARGO data with the altimeter information included (AltARGO05) is presented in Fig.1 for 2005. It exhibits all major features of the North Atlantic dynamic topography, i.e. the warm pool with a strong gradient toward the subpolar Gyre south of Greenland, the loop current in the Caribbean basin, a strong Labrador current which continues around the Grand Banks, a northward extension of the North Atlantic Current after its separation from the American coast at Cape Hatteras, and the Azores Current. Ocean currents are in agreement with the conventional oceanic knowledge and are used for the further analysis of the North Atlantic circulation and its interannual changes.
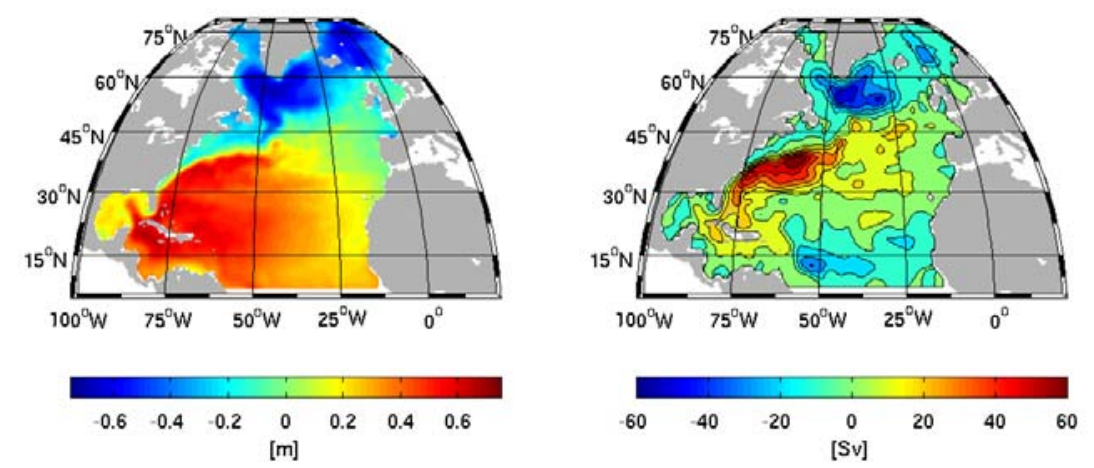

Fig. 1. Left panel: Modelled sea surface elevation (dynamic height) of the AltARGO05 experiment. Right panel: the corresponding barotropic stream function. 
We analyse the impact of using altimetry on the model solution. Comparing ARGO05, the experiment that excludes altimetry, with the independent altimeter sea surface (Fig. 2, left panel) we observe a large scale shift of about $80 \mathrm{~cm}$, from the Caribbean Sea to the subpolar gyre which shows that the circulation derived from hydrographic data alone is far from the observed reality. Using only ocean subsurface data produces a sea surface height with large scale spatial differences to altimeter and geoid observations. Thus, the additional information on the ocean circulation is necessary, and the obvious choice is to account for altimetry data in the model. The success of this choice (AltARGO05) is demonstrated in Fig. 2, right panel. It shows the differences of AltARGO05 to altimetric data which are an order of magnitude smaller than those for ARGO05. Referenced altimetry and the dynamic topography of the inverse model can be matched by small adjustments in $\mathrm{T}$ and $\mathrm{S}$ to an RMS misfit of $3 \mathrm{~cm}$.

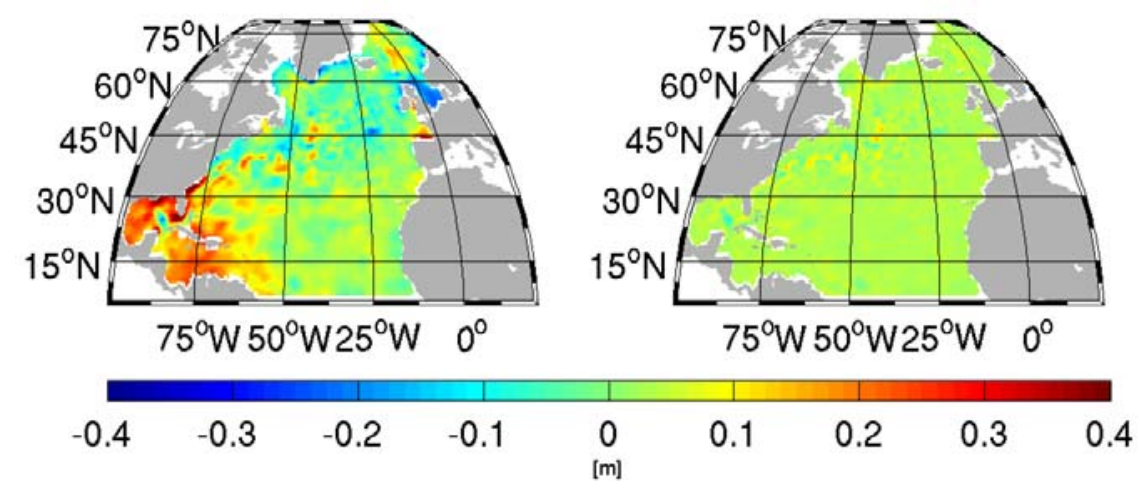

Fig. 2. Difference of modelled sea surface elevation and altimetry data in 2005. Based on ARGO only (left panel; ARGO05) and after including altimetry (right panel; AltARGO05).

One of the improvement by including altimetry is seen at an oceanographic section at $24^{\circ} \mathrm{N}$. The heat transport across this line computed from AltARGO05 is 1.24PW what compares perfectly with the values estimated by Lumpkin and Speer (2007) and Ganachaud and Wunsch (2003). Their estimates are 1.24 $\pm 0.25 P W$ and $1.27 \pm 0.15 \mathrm{PW}$, respectively. ARGO05 underestimates the heat transport across $24^{\circ} \mathrm{N}$ providing a value of only $0.89 \mathrm{PW}$.

In order to estimate the variability contained in ARGO and altimetry data the intercomparison of temporal change in modelled topography between years 2005 and 2006 is presented in Fig. 3. The left panel shows sea surface evolution based on ARGO (ARGO06-ARGO05), and the right panel displays the difference (AltARGO06-AltARGO05) when all data are used. 


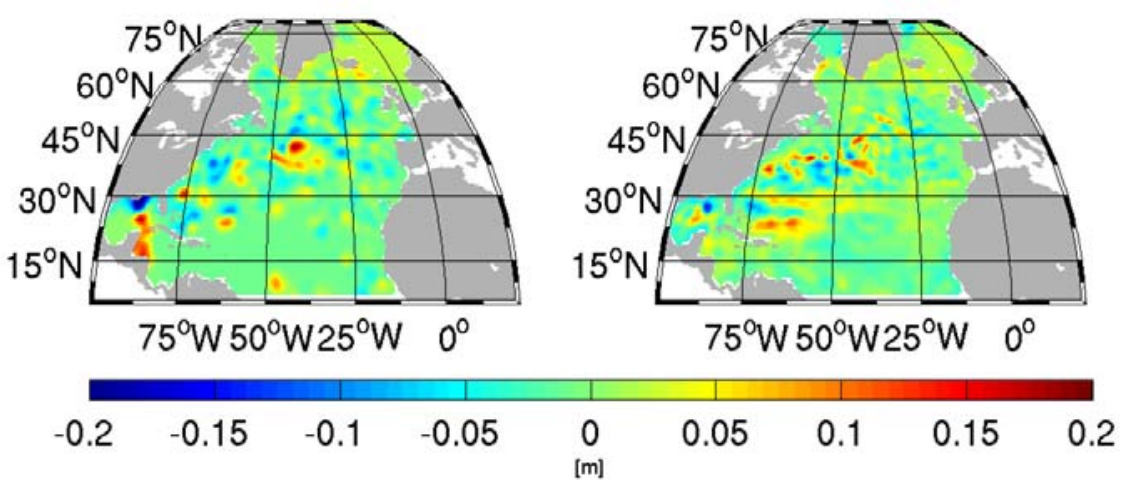

Fig. 3. Difference in modelled sea surface change based on ARGO only (left panel; ARGO06ARGO05) and after including altimetry (right panel; AltARGO06-AltARGO05).

Both patterns suggest a sea level rise of about $5 \mathrm{~cm}$ in Nordic seas. The Gulf Stream region and its extension are characterized by large activity. The interannual differences are up to $20 \mathrm{~cm}$. The differences in variability between the two plots are obviously due to the poor spatial sampling of ARGO data in comparison to altimetry. The corresponding change in the solution AltARGO06-AltARGO05 is similar to that of altimetry data (Fig.4). It contains slightly smaller and less sharp local anomalies, but takes into account a significant part of variability contained in the data.

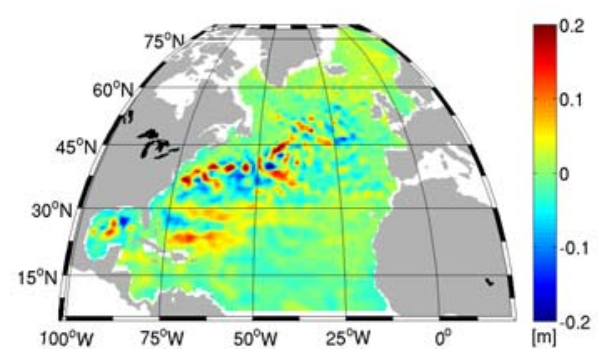

Fig. 4. Inter-annual change in altimetry data (2006-2005)

The model solution allows studying other characteristics of the circulation. We discuss the transport and its variability. Barotropic stream function has been determined for the inverse solution using all data (AltARGO05) and is depicted in Fig. 1 right panel. The gyre structures are well developed, the strength of the subpolar gyre is $50 \mathrm{~Sv}$ and is on the upper limit of most forward modelling studies (see e.g. Treguier et al., 2005). Considering the temporal changes 2006-2005 we notice differences of about 20Sv with the maximum in Gulf Stream region seen in 
both ARGO and AltARGO experiments (Fig.5, left and right panels, respectively) with more pronounced changes in AltARGO experiments. The changes in $\mathrm{T}$ and $\mathrm{S}$ fields are distinct and quite similar between ARGO only experiments and AltARGO solutions. In accordance to these findings, only smaller modifications in $\mathrm{T}$ and $\mathrm{S}$ are needed to compensate for the misfit in surface elevation. The variability in transports can be either explained by the bottom pressure change (which is loosely constrained during the assimilation to that of a forward solution (Sidorenko et al., 2005)) or the change in vertically integrated potential energy (which is the result of redistribution of $\mathrm{T}$ and $\mathrm{S}$ within the water column). Fig. 6 shows the difference in vertically integrated potential energy between ARGO06ARGO05 (left panel) and between AltARGO06-AltARGO05 (right panel).

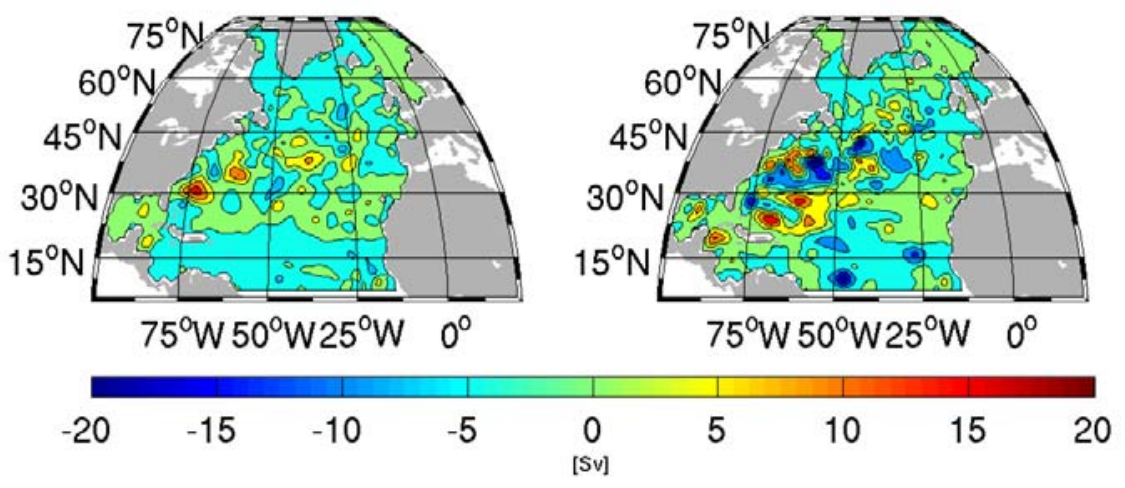

Fig. 5. Change in barotropic stream function (ARGO06-ARGO05 left and AltARGO06AltARGO05 right). Altimetry has a stronger impact on total transports then ARGO data have.

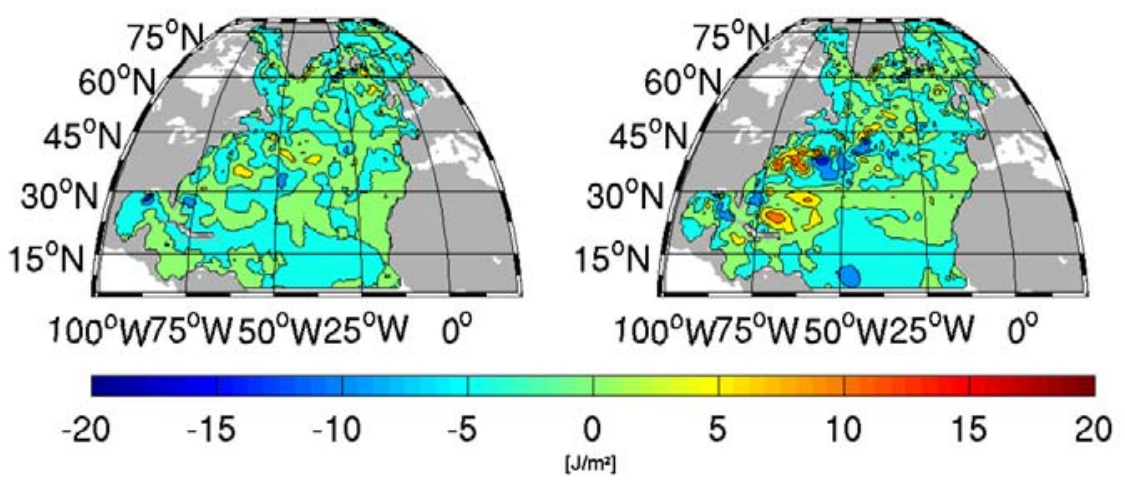

Fig. 6. Change in vertical integrated potential energy (ARGO06-ARGO05 left and AltARGO06-AltARGO05 right) scaled by $10^{-5}$. The transport changes induced by using altimeter data are produced by adjusting the vertical density structure in the model. 
It demonstrates that a significant part of the transport variability is due to the variability in vertically integrated potential energy. Thus, despite the fact that $\mathrm{T}$ and S adjustments done by IFEOM are mainly due to the ARGO anomalies, the modifications in potential energy are mainly from including altimetry. The latter in turn has a significant impact on transport variability.

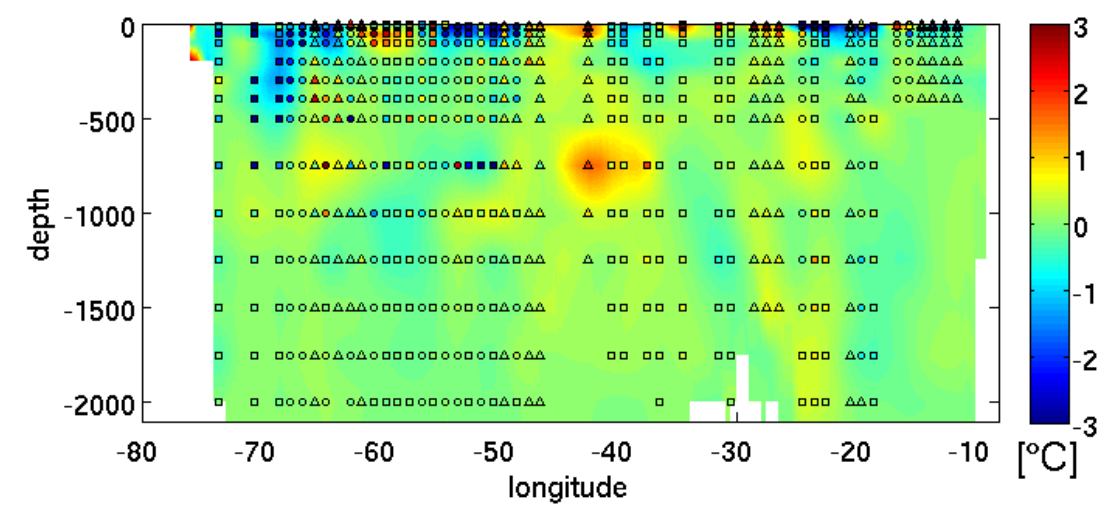

Fig. 7. Temperature change along a section through the North Atlantic at $37.5^{\circ} \mathrm{N}$. Difference between solutions AltARGO06-AltARGO05 is shown in background colour. The difference in the observations (2006-2005) at ARGO positions is depicted by colour coding the following symbols: both years are present in ARGO data (circle), if only one year (2005 square, 2006 triangle) is present the difference is computed using the climatology data instead of the missing year.

Fig. 7 shows the temperature change (AltARGO06-AltARGO05) across a section at $37.5^{\circ} \mathrm{N}$. It is dominated by the ARGO anomalies. The changes due to the altimetry assimilation are an order of magnitude smaller and are of the same sign within the entire depth (not shown here). The plot demonstrates that the model takes into account even the transient signal which can be present in raw data. The pattern of positive anomaly at about $40^{\circ} \mathrm{W}$ corresponds to an unstable profile measurement (year 2005). This anomaly is partly captured by IFEOM (which accounts for the whole available information) and results in stable model solution.

\section{Summary and Conclusions}

The quasi-stationary circulation of the North Atlantic is estimated for the years 2005-2006 using ARGO, GRACE and altimetry data. The assimilation technique has been used to reduce the misfit between data and model by adjusting $\mathrm{T}$ and $\mathrm{S}$ fields. It is shown that inclusion of the additional information from altimetry significantly changes the estimates of transports and variability. The sea level rise between 2005 and 2006 of about $5 \mathrm{~cm}$ in the Nordic seas is shown to be present in both, ARGO and altimetry data. Both datasets also reveal large variability in the Gulf Stream region and its extension which contributes to the estimated inter- 
annual differences by about $20 \mathrm{~cm}$. The Gulf Stream region shows the transport variability of about 20Sv in maximum. The changes are more pronounced for the simulations including altimetry data despite the fact that using altimetry leads to only small additional adjustments in $\mathrm{T}$ and $\mathrm{S}$. These adjustments in turn modify the vertically integrated potential energy significantly, which explains the transport variability. Thus, the vertically integrated potential energy anomaly shows that the transport variability is dominated mainly by the altimetry information while the major changes in $\mathrm{T}$ and $\mathrm{S}$ are explained by the ARGO data.

Acknowledgement. This is publication no. GEOTECH-XXX of the GEOTECHNOLOGIEN programme of BMBF, grant 03F0434B.

\section{References}

Ganachaud A, Wunsch C (2003) Large-Scale Ocean Heat and Freshwater Transports during the World Ocean Circulation Experiment. J. Climate, 16, 696-705

Gouretski VV, Koltermann KP (2004) WOCE Global Hydrographic Climatology. Bundesamt für Seeschifffahrt und Hydrographie, Hamburg und Rostock, Germany

Guinehut S, Coatanoan C, Dhomps A-L, Le Traon P-Y, Larnicol G (2009) On the Use of Satellite Altimeter Data in Argo Quality Control. J. Atmos. Oceanic Technol., 26, 395-402

Ivchenko VO, Danilov SD, Sidorenko DV, Schröter J, Wenzel M, Aleynik DL (2007) Comparing the steric height in the Northern Atlantic with satellite altimetry. Ocean Sci., 3, 485-490

Kivman G, Danilov S, Fritzsch B, Harig S, Reick C, Schröter J, Seufer V, Sidorenko D, Staneva $\mathrm{J}$ (2005) Improved estimates of the oceanic circulation using the CHAMP geoid. Earth Observation with CHAMP, Results from Three Years in Orbit, Springer-Verlag, Berlin, Heidelberg, New York 211-216.

Losch M, Schröter J (2004) Estimating the circulation from hydrography and satellite altimetry in the Southern Ocean: limitations imposed by the current geoid models. Deep-Sea Res. I, 51 (9), 1131-1143

Lumpkin R, Speer K (2007) Global Ocean Meridional Overturning. J. Phys. Oceanogr., 37, 2550-2562

Reigber C, Schmidt R, Flechtner F, König R, Meyer U, Neumayer K-H, Schwintzer P, Yuan Zhu S (2005) An Earth gravity field model complete to degree and order 150 from GRACE: EIGEN-GRACE02S. Journal of Geodynamics 39(1), 1-10

Rio MH, Hernandez F (2004) A mean dynamic topography computed over the world ocean from altimetry, in situ measurements, and a geoid model. J. Geophys. Res., 109, C12032

Rio MH, Schaeffer P, Lemoine JM, Hernandez F (2005) Estimation of the ocean Mean Dynamic Topography through the combination of altimetric data, in-situ measurements and GRACE geoid: From global to regional studies. Proceedings of the GOCINA international workshop, Luxembourg

Sidorenko D, Danilov S, Kivman G, Schröter J (2005) On the use of a deep pressure gradient constraint for estimating the steady state ocean circulation from hydrographic data. Geophysical research letters, doi: 10.1029/2005GL024716

Stammer D, Wunsch C, Giering C, Eckart C, Heimbach P, Marotzke J, Adcroft A, Hill CN, Marshall J (2002) The global ocean circulation during 1992-1997, estimated from ocean observations and a general circulation model. J. Geophys. Res., 107 (C9), 3118-3145 
Stammer D, Wunsch C, Giering C, Eckart C, Heimbach P, Marotzke J, Adcroft A, Hill CN, Marshall J (2003) Volume, heat and freshwater transports of the global ocean circulation 19932000, estimated from a general circulation model constrained by World Ocean Circulation Experiment (WOCE) data. J. Geophys. Res., C1 3007

Treguier AM, Theetten S, Chassignet EP, Penduff T, Smith R, Talley L, Beismann JO, Böning C (2005) The North Atlantic Subpolar Gyre in Four High-Resolution Models. J. Phys. Oceanogr., 35, 757-774

Wenzel M, Schröter J (1998) Combined assimilation of altimetric and hydrographic data. AVISO newsletter, 6, 122-124

Wenzel M, Schröter J, Olbers D (2001) The Global ocean circulation during 1992 -1997, estimated from ocean observations and a general circulation model. Prog. in Oceanogr., 48 (C9), 73-119

Wenzel M, Schröter J (2002) Assimilation of TOPEX/Poseidon data in a global ocean model: Differences in 1995-1996. Physics Chem. Earth, 27, 1433--1437 